\title{
Mental incapacity: some proposals for legislative reform
}

\author{
J V McHale University of Manchester, Manchester
}

\begin{abstract}
While the decision of the House of Lords in $\mathrm{Re} F$ in [1990] clarified somewhat the law concerning the treatment of the mentally incapacitated adult, many uncertainties remained. This paper explores proposals discussed in a recent government green paper for reform of the law in an area involving many difficult ethical dilemmas.
\end{abstract}

(Fournal of Medical Ethics 1998;24:322-327)

Keywords: Law; mental incapacity; best interests; clinical research; advance directives; withdrawal of treatment

The House of Lords decision in $\operatorname{Re} F,{ }^{1}$ provided guidance to health care professionals regarding the basis on which treatment procedures may be undertaken on the mentally incompetent adult. Subsequently there was some judicial exploration of the boundaries of such treatment decisions, ${ }^{2}$ but many complex issues remained unresolved. For example, it was widely argued that the involvement of the mentally incompetent adult in many non-therapeutic procedures such as clinical trials and genetic screening was of questionable legality. ${ }^{3}$ In the light of such uncertainty comprehensive clarification of the existing legal position was required. In 1995 the Law Commission published their report on Mental Incapacity ${ }^{4}$ following their previous consultation papers on the subject. ${ }^{5}$ The report considered the existing scope of English law concerning the care and treatment of the mentally incompetent adult and made recommendations for reform which, if enacted, would result in a broad statutory framework for the care and treatment of such adults. The report met with support from academic commentators, ${ }^{6}$ however, there was some controversy flowing from its recommendations for example, in relation to advance directives. There were some misconceptions that the report would amount to the legalisation of euthanasia. Eventually the previous Conservative administration decided not to take the proposals further (Lord Chancellor's Department, press release, 16 January 1996). However, the new Labour administration has revived the report. In December 1997 the government issud a green paper entitled Who Decides? ${ }^{7}$ Broad्] speaking the government has accepted the pinoposals of the Law Commission, but has invited further consultation on certain specific issuges. This article considers the proposals for a statuto? framework for the treatment of those without capacity.

\section{The test for capacity}

The preliminary question in such cases is alwayd does this patient possess capacity to make thisglefision? The test for capacity proposed by thein Commission incorporated a diagnostic threshild and a functional test. ${ }^{8}$ The functional tes applicable only to those who could not satisfy gine diagnostic threshold because they were unableDto make a decision due to their "mental disabilit". This was defined as "a disability or disorder of he mind or brain, whether permanent or temporary, which results in an impairment or disturbance्e्ण of mental functioning". "This differs from the test of "mental disorder" used in the Mental Health 1983. (There were concerns expressed to the I Commission that use of such a term could legad some to regard the new law as only applicable with regard to psychiatric patients). The functional test proposed by the Law Commission was along the lines of that stated by Thorpe $\mathrm{J}$ in $\operatorname{Re} C,{ }^{10}$ nan whether the individual could comprehend atid retain the information given to him/her, whetwer he/she believed the information and whether he/she used the information to arrive at a choice. A persen would lack capacity if he/she were unable to understand or retain the information relevant to the decision or were unable to make a decision basedळ్n that information. Incapacity is not to be equated with irrationality. The green paper emphasised twat the fact that a person has made an irratiofal decision by itself does not mean that the person lacks capacity. ${ }^{11}$ Assessing capacity is inevitab a matter which requires great care and sensitiety. The government has accepted the Law Commission's recommendation that there should be a code 
of practice providing guidance to health care professionals. ${ }^{12}$ The practical ramifications of these proposals need of course to be carefully examined. How will such assessments be made and how validated? As Delaney has commented: "How realistic is it to expect carers to repeat the assessment process and how easy will it be to challenge assessments?" As she goes onto argue: "this part of the green paper seems underwritten; to leave all details to a future code rather defeats the object of a consultation exercise now taking place". ${ }^{13}$

\section{Best interests}

In $\operatorname{Re} F$ the House of Lords indicated that while no one had the power to consent on behalf of a patient, treatment was to be given on the basis of necessity, where this was in the "best interests" of an adult who lacks capacity. Best interests was to be referable to the Bolam test of the responsible body of professional practice. The Law Commission examined the possible options - a best interests test or a substituted judgment test, in which the decision is made on the basis of the approach the patient would have taken had he/she had capacity. While opting for the former, the best interests approach which it adopted differed from that of $\operatorname{Re} F$. Rather than a Bolam-based test the report set out a number of criteria which should be considered when assessing a patient's best interests:

"The ascertainable past and present wishes and feelings of the person concerned and the factors the person would consider if available to do so; the need to permit and encourage the person to participate or improve his or her ability to participate as fully in anything done for and any decision affecting him or her; the views of other people whom it is appropriate and practical to consult about the person's wishes and feelings and what would be in his or her best interests; and whether the purpose for which any action or decision can be as effectively achieved in a manner less restrictive of the person's freedom of action." 14

The government accepted these in principle but invited views as to their application in practice. Questions raised include: how should the decision maker deal with any differences of opinion which may arise between those consulted, and how far will health professionals be required to make enquiries of interested parties and what are the legal consequences should they fail to do so. Aware, obviously, of the social and cultural dimensions of the complex decision-making process, the government has invited views as to whether the guidance "should take into account religious/cultural factors in establishing a person's best interests? If so, how could this most effectively be done?" Furthermore, it was asked to what extent relatives and carers can be expected "to put the interests of the person without capacity entirely before their own, especially if their own welfare or that of another relative or close friend is at stake" ? ${ }^{15}$ This highlights the fact that while such treatment decisions focus on the best interests of the individual, in practice, in a case such as the proposed sterilisation of a mentally incompetent woman being cared for by an aging parent, it may be difficult to divorce the individual from the setting within which treatment decisions are made. ${ }^{16}$

\section{General authority to act reasonably}

After the decision in $\operatorname{Re} F$ considerable uncertainty surrounded the legality of many everyday decisions made regarding adults without capacity, by family members or carers. The Law Commission recommended the creation of a general authority to act reasonably, and then went on to recommend that it should be "lawful to do anything for the personal welfare or health care of a person who is, or is reasonably believed to be, without capacity in relation to the matter in question if it is in all the circumstances reasonable for it to be done by the person who does it". ${ }^{17}$ The government invited views as to whether this definition was appropriate. ${ }^{18}$ This general authority would exclude, for example, detention/ compulsion or the doing of anything to which the individual objects. ${ }^{19}$ Involvement of the adult without capacity in the decision-making process is, of course, to be welcomed. Limitations regarding detention and compulsion may prove problematic and indeed it may be the case that in certain instances, without compulsion, treatment, in practice, proves impossible.

\section{Advance statements}

There have been many calls for the clarification of the legal position regarding advance statements (referred to by many as advance directives), partly motivated by the developments in modern technology, with their ability to prolong lifespan and the fact that certain individuals do not want to live unless at least "half-way normally" for example, persons who are HIV positive, are concerned to have the ability, at least to a certain extent, to manage the end of their life. There is presently no legislation regarding advance statements in the United Kingdom. However, the validity of some form of advance statements has long been recognised; Jehovah's Witness patients can quite clearly legitimately reject blood transfusions even where this may result in their death and 
this was confirmed in cases such as $\operatorname{Re} T^{21}$ Development of advance statements also received the support of the House of Lords Select Committee on Medical Ethics. ${ }^{22}$ The British Medical Association issued helpful guidance on advance statements in $1995 .{ }^{23}$ None the less there appears to be considerable hesitancy in practice amongst health care professionals as to the recognition of advance statements. The advantage of the introduction of legislation on this issue, something which the Law Commission favoured, is that it provides guidance and reassurance for patients and health care professionals alike. However, the government is not convinced as to the need for legislation and stated that "there may be some merit in postponing further policy development in this area until there has been more opportunity to consider current case law and codes of practice". ${ }^{24}$ The green paper invited consultation on the Law Commission's definition of an advance refusal. The Law Commission defined this as "a refusal made by a person aged 18 or over with the necessary capacity, of any medical, surgical or dental treatment or other procedures and intended to have effect at any subsequent time when he or she may be without capacity to give or refuse consent". ${ }^{25}$ Both the Law Commission and the government emphasised that an advance statement cannot make lawful an action which is otherwise unlawful. The government stressed that it had no plans to legalise mercy killing. ${ }^{25}$ Patients are also not to be able to insist upon treatment which is not supported by medical opinion..$^{26}$ The government endorses the Law Commission's recommendation that advance statements, in contrast with the position in the USA, should not be applicable only in a situation in which the individual is in a terminal condition. ${ }^{27}$ As with the operation of the best interests test the government commented that the advance statement is not "to be seen in isolation, but against a background of doctor/patient dialogue and the involvement of other carers who may be able to give an insight into what the patient would want in the particular circumstances of the case."28 The government asked whether the safeguards would be adequate to ensure that advance statements would not unintentionally prevent the use of medical procedures developed after the statement had been drafted.$^{29}$ One concern regarding the use of advance statements is that some individuals, perhaps including the vulnerable elderly, may be under pressure to execute them and views were sought as to how to ensure that advance statements are the result of an informed, considered choice free from undue influence. ${ }^{30}$ The operation of such statements may also prove problematic in certain particular situations. Con- sultation was invited by the government $\frac{\Omega}{\text { on }}$ specific issues, such as whether an advance tre $\overrightarrow{\overrightarrow{g t}}-$ ment refusal should deal expressly with situations such as the woman who subsequently becomets pregnant. ${ }^{31}$ It is proposed that where a patients life is in danger an advance refusal should only applicable if the patient has explicitly acknowedged the risk of death. ${ }^{32}$ Views were also soughit regarding whether in the interests of nursing staff and other patients, advance refusals shoûld exclude "basic care", including maintenance. bodily cleanliness and provision of oral nutrition/ hydration. Concerns were expressed that the consequence could be force feeding. ${ }^{33}$

\section{Special authorisation}

The House of Lords in $R e F$ suggested that in the case of certain procedures undertaken on meatally incompetent adults, such as non-therapeufic sterilisations, it would be appropriate to seek prior judicial approval. ${ }^{34}$ The Law Commission was aßo of the view that in certain situations judicfal approval, or at the very least some form of "seco雨 opinion" should be obtained. Procedures whigh would require judicial approval, or approval givesn under a power in regard to a continuing power $\theta f$

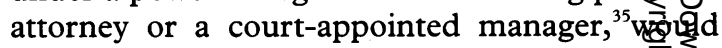
include for example, sterilisation proce which would render a person permanengly infertile, save where such procedures were for treatment of a disease of the reproductive organs or to relieve existing detrimental effects fof menstruation. Secondly, the Law Commission was of the view that in some instances obtain authorisation in the form of a second doctor's cerrtificate might be more appropriate than judic̣ial authorisation, for instance in the context of stefilisation for the purpose of relieving detrimentral effects of menstruation or abortion. ${ }^{37}$ On question of special authorisation the green paper differed from the Law Commission in a numberof respects. For example, with regard to sterilisat for relieving detrimental effects of menstruation the green paper noted that the consequenceorf such a procedure might be that an individual was rendered permanently infertile. ${ }^{38}$ The governmefnt invited consultation as to whether such prosedures should require judicial approval. Similaty, views were also sought as to whether donation 5 of blood, bone marrow and both regenerative non-regenerative tissue by a mentally incompetent person should require judicial authorisatio ${ }^{39}$ The Law Commission had recommended judiçal approval in the context of bone marrow and n\&nregenerative tissue. In contrast the government differed from the Law Commission with regard to the commission's recommendation that a second 
doctor's certificate should be required in the context of abortion, believing that the existing safeguards contained in the Abortion Act 1967, with its provision for approval by two doctors, were sufficient. ${ }^{40}$

\section{Departing from the best interests criteria}

While the basis for undertaking procedures on the mentally incompetent adult was to be generally the "best interests" test, there could be circumstances in which procedures might be justifiable even though it could not be said that they were in the patient's own best interests. One such instance was the withdrawal of artificial nutrition/hydration from a person who was unconscious, with no activity in the cerebral cortex and who had no prospect of recovery. The type of situation envisaged is that of the Bland case. ${ }^{2}$ The government solicited views as to what amounts to "no prospect of recovery" in such cases. Referring to the guidelines issued by the Royal College of Physicians, it asked for views on the suitability of the definition: "patients who have no prospect of recovery who are either unconscious or in a permanent vegetative state." ${ }^{41}$ The Law Commission was of the view that when making such treatment withdrawal decisions, while best interests was not an applicable test, at the same time reference could be made to the criteria in the best interests checklist. ${ }^{42}$ This was a somewhat controversial conclusion and, as the green paper commented, some may regard such patients as having best interests. The green paper invited views as to whether in considering continuance/ withdrawal from patients in a persistent vegetative state (PVS), regard should be given to the patient's best interests. ${ }^{43}$ In the Bland case the House of Lords emphasised the exceptional nature of the case and the desirability of such cases in future being referrable to the courts. ${ }^{44}$ The government also consulted on the Law Commission's comment that a point may be reached, after a bank of case law had developed, when it would be possible to make such decisions by reference to a second-opinion procedure rather than by reference to the courts. ${ }^{45}$ In the light of certain recent evidence suggesting difficulties in diagnosis of PVS and the widely publicised case of Andrew Devine, who recovered from a PVS state, it may be some time before such decisions are left to other than judicial determination. ${ }^{46}$ The government also invited consultation on the Law Commission's proposal that in certain instances it is legitimate to undertake procedures with the intention of benefiting persons other than a mentally incompetent adult. Such procedures include elective ventilation and genetic screening. ${ }^{47}$

\section{Clinical research}

The government invited views as to whether research procedures which would not benefit the mentally incompetent adult should be allowed and as to whether the safeguards proposed by the Council of Europe in its Convention on Biomedicine and Human Rights are sufficient to ensure protection of the patient's interest. ${ }^{48}$ The convention sets out a number of criteria with regard to the performance of such research, including: the fact that research of comparable effectiveness cannot be undertaken upon competent adults; the results of the research will benefit the individual's health; necessary consents have been given, and the individual concerned does not object. ${ }^{49}$ (At present the UK government is considering becoming a signatory to this convention). After $\operatorname{Re} F$ the legality of the performance of non-therapeutic research upon mentally incompetent adults was uncertain. ${ }^{50}$ The green paper sought views as to whether such research should be allowed. The Law Commission had recommended that a new committee be established with the task of scrutinising proposals for the involvement of mentally incompetent adults in non-therapeutic trials. ${ }^{51}$ Once initial approval had been given by this committee the involvement of individual adults would also require further approval by a third party, whether court, attorney or manager, although this would not be applicable in relation to observational research. ${ }^{52}$ The government, whilst accepting the second part of these recommendations cast doubt upon the appropriateness of the former and questioned the desirability of the creation of yet another body to be involved in the approval of clinical trials. ${ }^{53}$ Admittedly the proliferation of such ad hoc bodies may be a legitimate matter of concern. There may be difficulties of co-ordination between the appropriate bodies which would require further consideration. None the less there are positive advantages in referring such complex and sensitive issues to a specialist body rather than leaving the routine determination of such policy issues to be resolved at a local level.

\section{Powers of attorney}

While the Enduring Powers of Attorney Act 1985 provided that a person could be appointed to manage the financial affairs of a person who had become incompetent these powers did not relate to the medical treatment of such persons. The Law Commission proposed that an individual should be able to appoint a "treatment proxy". ${ }^{54}$ Others have been more sceptical as to the effectiveness of treatment proxies. The House of Lords Select Committee on Euthanasia, for instance, was of the view that these proposals were 
vulnerable to the same potential problems as advance directives - for example, the choice of proxy becoming out of date - and also to practical difficulties with regard to the choice the patient may have made. ${ }^{55}$ The green paper noted these concerns. While the government was in broad agreement with the Law Commission's proposals, views were invited, in particular regarding what safeguards were necessary to ensure that such proposals operated in practice. ${ }^{56}$ The government sought guidance as to whether the attorney should be able to refuse treatment where there was no explicit advance refusal. ${ }^{57}$ They invited consultation as to whether the power to appoint a treatment attorney should apply not only to those over 18 , but also to those between 16 and 18 as where "in the absence of an effective parental relationship they may have good reason to nominate an adult to take health treatment decisions for them if they become incapacitated". ${ }^{58}$ This recommendation, however, seems somewhat at odds with the recognition made earlier in the green paper where it is noted that the court or the person exercising the power of parental responsibility may exercise treatment decisions regarding persons between 16 and 18 in the face of opposition from the minor. ${ }^{59}$ (This was the reason behind the Law Commission's recommendation that both advance directives and power of attorney should only be applicable to those over 18.) The government accepted the recommendation that the power of attorney could be amended/withdrawn at any time. ${ }^{60}$ One proposal which the Law Commission rejected in its report, was that the donor's capacity to execute a power of attorney should be subject to a certificate from a doctor and a solicitor: they regarded this as being overly intrusive. However, the government was of the view that this could help to prevent abuse of the power and invited consultation on this point. ${ }^{61}$ The government accepted that the terms of a continuing power of attorney should be capable of variation by the court where this is in the donor's best interests, although the donee must be willing to take on this additional responsibility. ${ }^{62}$ The government also accepted that the court should have a role in determining the scope of such powers.

\section{Concluding thoughts}

The revival of the Law Commission's report on mental incapacity, with the prospect of legislation in the not too distant future, is to be welcomed. The legal boundaries of decision making for the adult without capacity require clarification to safeguard the position of both those without capacity and those involved in their care and treatment. Persons who wilfully neglect those under their care should, it is proposed, be capable of criminal prosecution. ${ }^{63}$ Health care professionals who comply with directions under an advan statement are to be able to act in the knowledge theat they will not be subject to subsequent le $\mathrm{g}^{\mathrm{g}} \mathrm{l}$ proceedings ${ }^{64}$ However, the proposals themselges may give rise to certain difficulties. As has begn noted by Bartlett, ${ }^{65}$ the framework of the $L \frac{50}{10}$ Commission report is complex, with its combia tion of requirements for judicial approval, second opinion, application of best interests test in some situations and not others etc. This highlights need for a clear and comprehensive code $\overrightarrow{-f}$ practice. The Law Commission proposed theat where cases were appropriate for reference to jü cial determination these should be referred to a "judicial forum", a specialist jurisdiction in the form of an enhanced court of protection, whith would have the power to deal with issues of finanke, health and welfare. There are perceptible advaltages in such specialisation. However, this woutd require much practical restructuring of the cofit system. ${ }^{66}$ There is a further practical issue. T劦 report covers a wide range of decisions made Qn behalf of those without capacity. To enact the whgle report will require the devotion of a consideraje amount of parliamentary time. In an alseady overcrowded parliamentary agenda the prosperof such wholesale legislative reform may be unrastic. Instead there is the prospect that parts, rather than the whole of the report, will ultimately क़ेe enacted, something which many are likely to regarisd as unsatisfactory. Furthermore, resource implie tions arise from the introduction of such changes-a fact highlighted in the report itself. As Stone cowments: "The document confirms that a substantrial contribution to the additional costs of refo would need to be met from actual or potential be eficiaries of the new procedures, which some Will surely perceive as a tax on the mentaly incapacitated". ${ }^{67}$ The fate of the Law Commissiont's report remains to be seen, much will depend upon whether consensus can be achieved on many dificult ethical issues.

\section{Acknowledgment}

The author would like to thank Professor Margaret Brazier for helpful comments on an earber draft of this article. The author takes full respensibility for all opinions expressed and any errळ్rs which may remain.

Fean McHale, LLB, MPhil, is Senior Lecturerộ, Law, Faculty of Law, University of Manchesiber, Manchester.

\section{References}

1 [1990]1 AC 1. 
2 See for example, Airedale NHS Trust $\mathrm{v}$ Bland [1993]AC 789; Re W (Mental Patient) [1993]1 FLR 381.

3 See for example Mason JK, McCall Smith RA. Law and medical ethics. London: Butterworths, 1994: 362, though see now in relation to the donation of bone marrow, $R e Y[1996] 2$ FLR 791.

4 Law Commission Mental incapacity. Law Com, 231, HMSO 1995.

5 Law Commission. Mentally incapacitated adults and decision making: a new jurisdiction (consultation paper no 128, 1993), Law Commission. Mentally incapacitated adults and decision making: medical treatment and research (consultation paper no 129, 1993); Law Commission. Mentally incapacitated and other vulnerable adults: public law protection (consultation paper no 130,1993 ) and see generally the special issue of the Medical Law Review devoted to an examination of the consultation papers which preceded the report. Medical Law Review 1994;2: $1-92$.

6 See for example Gunn MJ. Mental incapacity - the Law Commission's report. Child and Family Law Quarterly 1995;7:20922.

7 Lord Chancellor's Department. Who decides? Making decisions on behalf of mentally incompetent patients. Consultation paper, Dec 1997

8 See reference 4: paras 3.3-3.13. See generally the discussion in Wilson P. Mental incapacity. Medical Law Review 1996;4: 227 and see reference $6: 211-12$.

9 See reference 4: draft bill clause $2(2)$ b.

10 [1994]1 WLR 290.

11 See reference 7: paras 3.20-3.21.

12 See reference 7: para 3.16.

13 Delaney L. Responsibility and capacity.Health Care Risk Report 7, 1998;4:70.

14 See reference 4 : draft bill clauses 3(2).

15 See reference 7: para 3.24.

16 See further Grubb A. Treatment decisions: keeping it within the family. In: Grubb A, ed. Choices and decisions in health care. Chichester: John Wiley, 1993.

17 See reference 4: draft bill clause 4 .

18 See reference 7: paras 3.26- 3.28.

19 See reference 4: para 4.33.

20 See for example Cruzan v Missouri Department of Health 497 US 261, 110 SCt 2841(1987)

21 [1992]4 All ER 649.

22 House of Lords Select Committee on Medical Ethics. HL paper 21 (1993-4): paras 181-215.

23 British Medical Association. Advance statements about medical treatment: code of practice with explanatory notes. London: BMJ Publishing Group, 1995.
24 See reference 7 : para 4.7.

25 See reference 7: para 4.15

26 See reference 7: paras 4.14-4.15

27 See reference 7: para 4.24

28 See reference 7 : para 4.18

29 See reference 7: para 4.17 .

30 See reference 7: para 4.23 .

31 See reference 7: para 4.29

32 See reference 7 : paras $4.26-7$.

33 See reference 7: para 4.35-4.37.

34 See reference 1: 10 .

35 See reference $4:$ paras 6.3-6.5

36 See reference 4: para 6.4 .

37 See reference $4:$ paras $6.7-6.11$

38 See reference 7: para 5.9.

39 See reference 7: para 5.13

40 See reference 7: paras 5.19-5.20.

41 See reference 7: paras 5.25.

42 See reference 4: paras 6.22 .

43 See reference 7: para 5.30 .

44 See Bland at reference 2: see for example Lord Goff.

45 See reference 7: para 5.28

46 See Andrews $\mathrm{K}$ et al. Misdiagnosis of the persistent vegetative state: retrospective study. British Medical fournal 1996:313:13.

47 See reference 7 : paras 5.33

48 DIR/JUR (96) 14.

49 See reference 48: article 16 .

50 See reference 4: para 6.29 .

51 See reference 4: para 6.33

52 See reference 4:para 6.37 .

53 See reference 7: para 5.41

54 See reference $4:$ part VII of the report.

55 See reference 22: para 270.

56 See reference 7: para 6.9 .

57 See reference 7: para 6.25 .

58 See reference 7: para 6.29 .

59 See reference 7: para 4.21 and also $\operatorname{Re} R$ (a minor) (medical treatment)[1991]4 All ER 177 and $\operatorname{Re} W$ (a minor)(medical treatment) [1992]2 All ER 627

60 See reference 7: para 6.31 .

61 See reference 7: para 6.40

62 See reference 7: para 6.51-2

63 See reference 7: para 3.40

64 See reference 7: para 4.30

65 Bartlett P. The consequences of incapacity. [1997]4 Web fCLI (this is an internet journal thus no page numbers are cited).

66 See reference 4: part $x$ and see reference $7:$ chs 7 and 9.

67 Stone J. Mental incapacity:reform at last? Solicitors' fournal 1998;142:259. 